\title{
Spinal muscular atrophy with respiratory distress type 2
}

INSERM

\section{Source}

INSERM. (1999). Orphanet: an online rare disease and orphan drug data base. Spinal muscular atrophy with respiratory distress type 2. ORPHA:404521

Spinal muscular atrophy with respiratory distress type 2 is a rare, genetic, motor neuron disease characterized by prog ressive early respiratory failure associated with diaphragm paralysis, distal muscular weakness, joint contractures, and axial hypotonia with preserved antigravity limb movements. Phenotype overlaps considerably with SMARD type 1 but is differentiated by a mutation in a different gene. 